\title{
PEMANFAATAN E-WASTE PRINTED CIRCUIT BOARD MENJADI ARMATUR LAMPU
}

\author{
Aileen Gabriela Susiana 1), Gracia Ika Gunawan') \\ ${ }^{1}$ Fakultas Seni dan Desain, Universitas Kristen Petra \\ email: m41416015@john.petra.ac.id \\ ${ }^{2}$ Fakultas Seni dan Desain, Universitas Kristen Petra \\ email: m41416002@john.petra.ac.id
}

\begin{abstract}
Electronic Waste, abbreviated as E-waste, is a product of no longer used electronic devices. E-waste also considered as dangerous, as it contains $2,70 \%$ of toxic substances. The sheer amount of electronic waste produced by citizens of Indonesia alone means that any semblance of effort is needed to process these wastes into something which has usage and economic value. Printed Circuit Board or shorten as PCB is a component structure of an electronic devices, unused electronic devices still has PCB left intact inside of them, which make $P C B$ also an electronic waste. This design was done to reuse $E$-waste, in this case is $P C B$ into an interior accessory. Other than reducing the amount of electronic waste in our vicinity, this design has another goal to increase the ingeniousness of the human resources who are going to realize the design into the final product, also to teach and engage the public to develop a more creative way of thinking in solving environmental problems of our vicinity. The final product of this design is a lamp armature made of PCBs. The surface of $P C B$ has intricate pattern and a futuristic look to it, which when processed into an interior accessory could increase the visual esthetic of a room. Lamp armature itself has many variations, and the chosen variant for this design is table lamp, and the lamp will be able to be placed on a nightstand and act as a sleep lamp. To strengthen the armature structure, black painted iron was used as a place where the $P C B$ will be arranged and the lamp placed. BMC (Business Model Canvas) was used to analyze the market and to help the marketing of the lamp armature. This lamp armature was designed to prove that even an electronic waste such as $P C B$ able to retain economic and usage value.
\end{abstract}

Keywords: e-waste, interior accessories.

\section{PENDAHULUAN}

Sampah elektronik atau biasa disebut $E$-waste (Electronic Waste) merupakan barang-barang elektronik yang sudah tidak terpakai sudah tidak terpakai seperti telepon genggam, printer, kulkas, radio, dan sebagainya. Bagian-bagian dari alat elektronik ini tidak bisa terurai secara alamiah dan harus ada penanganan secara khusus untuk pemusnahannya. Di dalam barang elektronik, biasanya terdapat komponen utama yang dinamakan PCB (Printed Circuit Board). Komponen ini akan menimbulkan sampah buruk ketika sudah menjadi $E$-waste yang dibiarkan menumpuk begitu saja. Dengan alasan tersebut, pengolahan limbah elektronik terutama PCB memerlukan penanganan yang tepat. Penanganan yang asal-asalan bisa menimbulkan dampak yang serius terhadap kesehatan dan lingkungan. Jika 1 orang indonesia membuang $3 \mathrm{~kg}$ limbah elektronik. Sementara, total limbah elektronik yang dibuang orang Indonesia: 745 kilo ton dan Indonesia juga belum memiliki banyak tempat pengolahan limbah elektronik.
Oleh karena itu, sampah ini tidak bisa dibiarkan menumpuk begitu saja melainkan harus diolah dan ditangani agar menjadi sesuatu yang mempunyai nilai guna dan nilai jual.

\section{KAJIAN LITERATUR}

\section{A. Limbah Elektronik (E-waste)}

Limbah elektronik terdiri dari komponenkomponen listrik dan peralatan elektronik yang sudah tidak digunakan maupun diinginkan lagi. Peralatan elektronik didefinisikan sebagai peralatan yang dioperasikan dengan menggunakan arus listrik atau memfungsikan medan magnet dan menggunakan voltage $0-1000 \mathrm{~V}$ untuk arus $\mathrm{AC}$ dan $0-1500 \mathrm{~V}$ untuk arus DC (Marwati, 2009).

Penjualan produk elektronik terus meningkat dan semakin canggih sejalan dengan inovasi-inovasi dari produsen produk elektronik dan gencarnya pemasaran ke berbagai negara berkembang seperti Indonesia (Fuada, 2013). Berdasarkan data yang diperoleh dari Asosiasi Telepon Seluler Indonesia, 
disebutkan bahwa pengguna ponsel Indonesia mencapai 180 juta pengguna pada akhir tahun 2010 (Astuti et al, 2012 dalam Sadah et al, 2015). Disebutkan pula bahwa pada tahun 2007 Indonesia memproduksi lebih dari 3 milyar unit peralatan elektronik rumah tangga dan perlengkapan IT, dan pada tahun yang sama, konsumsi tahunan televisi mencapai 4,3 juta unit sementara kulkas mencapai 2,1 juta unit dan AC dan mesin cuci masing-masing mencapai 900.000 unit (Hanafi et al dalam Astuti et al, 2012 dalam Sadah et al, 2015).

E-Waste yang dihasilkan, terkandung baik bahan beracun dan bahan berharga. Kandungan bahan berharga di dalamnya adalah besi, tembaga, aluminium, emas dan logam lainnya dalam E-Waste, dan jumlahnya lebih dari $60 \%$, sedangkan presentasi kuantitas bahan polutan berjumlah $2,70 \%$ dari volume total E-waste (Widmer et al, 2005 dalam Astuti et al, 2012). Menurut Gramatyka, Nowosielski, Sakiewicz (2007) secara umum limbah elektronik mengandung $40 \%$ logam, $30 \%$ plastik dan $30 \%$ bahan oksida. Limbah elektronik juga mengandung 20\% Tembaga (Cu), 8\% Besi (Fe), 4\% Timah (Sn), 2\% Nikel (Ni), 2\% Timbal (Pb), 1\% Seng (Zn), 0,2\% Perak (Ag), 0,1\% Emas (Au) dan 0,005\% Palladium (Pa). Selain itu mengandung polipropilen, polietilen, poliester dan polikarbonat yang berasal dari komponen berbahan plastik.

\section{B. Printed Circuit Board (PCB)}

Printing Circuit Board (PCB) atau Papan sirkuit cetak adalah sebuah papan yang berisi jalur/sirkuit konduktor yang menghubungkan komponen elektronik satu dengan komponen elektronik lainnya tanpa kabel. Papan PCB dibutuhkan hampir di setiap rangkaian peralatan elektronika, missal pada TV, Radio, rangkaian lampu LHE, HP dan sebagainya (Cahyono dan Ariani, 2014). PCB adalah salah satu komponen umum dalam komputer yang memiliki berbagai kandungan logam dan semikonduktor. Salah satu logam yang terdapat dalam PCB komputer atau yang biasa dikenal sebagai motherboards adalah emas (Behnamfard et al., 2013 dalam Alfanaar, 2015).

\section{Armatur Lampu}

Armatur lampu merupakan aksesoris interior yang berfungsi sebagai penutup yang bisa mendifusi cahaya dari lampu. Armatur lampu sendiri bentuknya bervariasi sehingga bisa meningkatkan nilai estetika dari ruang interior.

\section{III.METODE PENELITIAN}

Metode penelitian atau spesifiknya, metode perancangan yang digunakan oleh penulis adalah metode Design Thinking. Berikut merupakan langkahlangkah dari Design Thinking yang sudah dilakukan oleh penulis.

\section{A. Discovery}

Menemukan objek perancangan dengan memahami dan melakukan observasi akan keadaan yang ada di tengah masyarakat untuk memperoleh dasar perumusan masalah dan objek perancangan. Dari penelitian ini objek yang akan dirancang yaitu element pengisi interior (armatur lampu) yang berfungsi sebagai lampu tidur atau lampu penghias ruangan. Rumusan masalah yang diambil yaitu bagaimana pengelolaan sampah E-waste seperti Printed Circuit Board (PCB) menjadi suatu barang yang mempunyai nilai guna dan nilai jual dan mengapa sampah e-waste khususnya Printed Circuit Board (PCB).

\section{B. Interpretation}

Mengidentifikasi dan mengolah data hasil observasi. Kemudian diolah untuk dijadikan standar sehingga dapat melangkah ke tahapan selanjutnya dan dikelompokkan menurut sumber dan hasil data. Dalam tahap ini data-data berupa data lapangan mengenai sumber supply, mitra yang akan digunakan seperti tukang dan data-data tersebut dikumpulkan untuk menjadi acuan kebutuhan pengguna ke tahap berikutnya (programming).

\section{Ideate}

Ide dibentuk dan diwujudkan melalui sketsa dari ide awal. Mulai dari konsep sampai tahap perancangan berbentuk skematik desain. Berawal dari skematik desain ini kemudian dikembangkan menjadi hasil akhir produk desain. Dalam tahap ini dibuat beberapa alternatif sketsa armature lampu sesuai konsep yang telah ditentukan yang kemudian dipilih tiga desain akhir.

\section{Experimentation}

Pengimplentasian desain yang diterapkan dengan pembuatan prototype berdasarkan ide, konsep, dan skematik desain yang telah dibuat sebelumnya sehingga dapat lebih mudah dijelaskan. Dari desain yang ada dibuat mockup untuk mengetahui apakah konstruksi armature lebih kuat menggunakan bahan apa, apakah menggunakan rangka besi atau 
aluminium. Kemudian 3 desain terpilih dibuat prototype 1:1 untuk perealisasian produk agar dapat melanjutkan ke tahap berikutnya.

\section{E. Evolution}

Tahap yang dilakukan setelah selesai melakukan uji coba dan mendapatkan hasil untuk dievaluasi yang kemudian dibuat rencana untuk pengembangan produk sehingga dapat diproduksi dan dapat bermanfaat sesuai dengan tujuan awal produk ini dibuat. Produk yang telah jadi diuji coba dengan menjual produk tersebut melalui media sosial seperti instagram dan melalui offline yaitu mengikuti bazar.

\section{F. Test}

Pada tahap evaluasi produk, produk tersebut diperbaiki sesuai dengan hasil dari konsumen yang telah membeli dan mencoba produk ini. Solusi yang diberikan berupa solusi pengembangan desain jadi tidak hanya dibuat armature lampu namun juga dibuat menjadi beberapa produk aksesoris interior lainnya dan memperbaiki kekurangan produk tersebut dalam hal konstruksi.

\section{IV.HASIL DAN PEMBAHASAN}

\section{A. Discovery}

Pada tahap ini penulis melakukan brainstorming mengenai sampah e-waste mulai dari kegunaanya hingga kelebihan maupun kekurangannya. Selain itu juga penulis mencari referensi mengenai penggunaan $\mathrm{PCB}$ yang diterapkan dalam interior salah satunya sebagai aksesoris interior.

\section{B. Interpretation}

Pada tahap kedua ini penulis mulai melakukan survey pada mitra-mitra yang akan digunakan dan mulai dari mendata keperluan-keperluan apa saja yang akan digunakan dalam perancangan armatur lampu ini, mencari supply bahan baku perancangan produk ini yaitu melakukan survey harga pada mitra diantaranya pada toko listrik dan pada tukang besi di sekitar Jalan Siwalankerto, Surabaya.

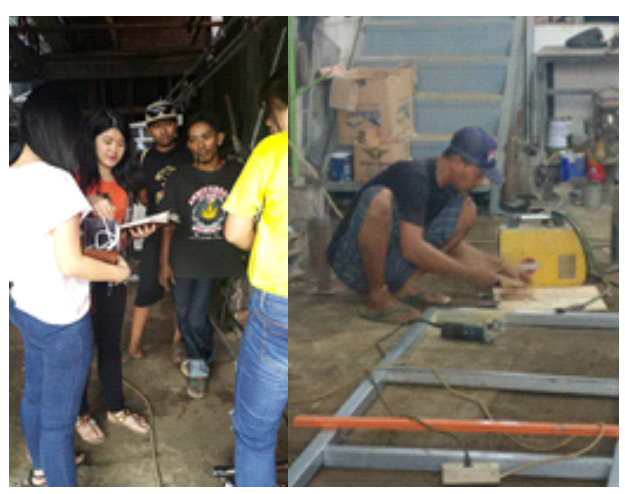

Gambar 1. Kunjungan ke Mitra Tukang Las dan Besi. (Susiana, 2019).

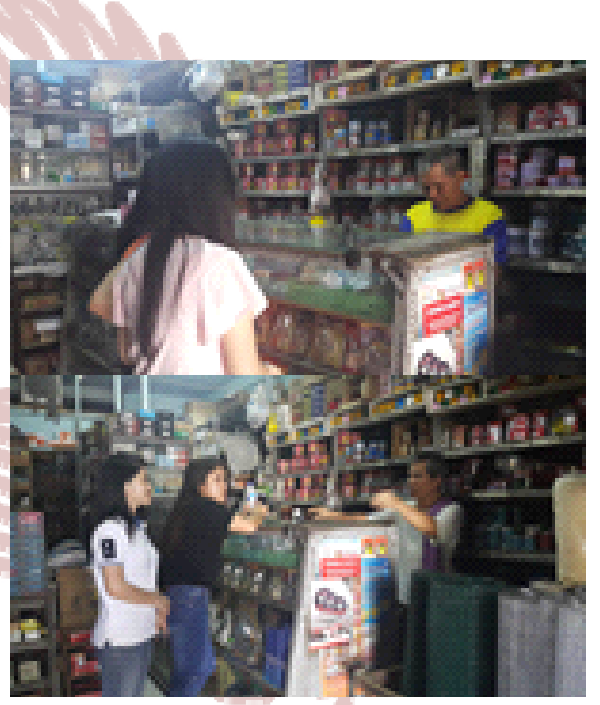

Gambar 2. Kunjungan ke Mitra Toko Listrik. (Susiana, 2019).

\section{Ideate}

Tahap Ideate adalah tahap programming desain atau tahap skematik desain. Skematik desain yang telah dibuat lalu diuraikan sehingga menghasilkan beberapa alternatif desain atau sketsa desain armatur lampu yang berbahan dasar PCB.

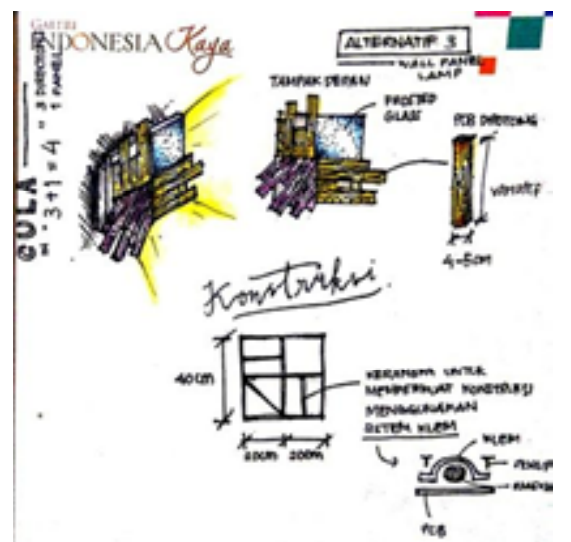



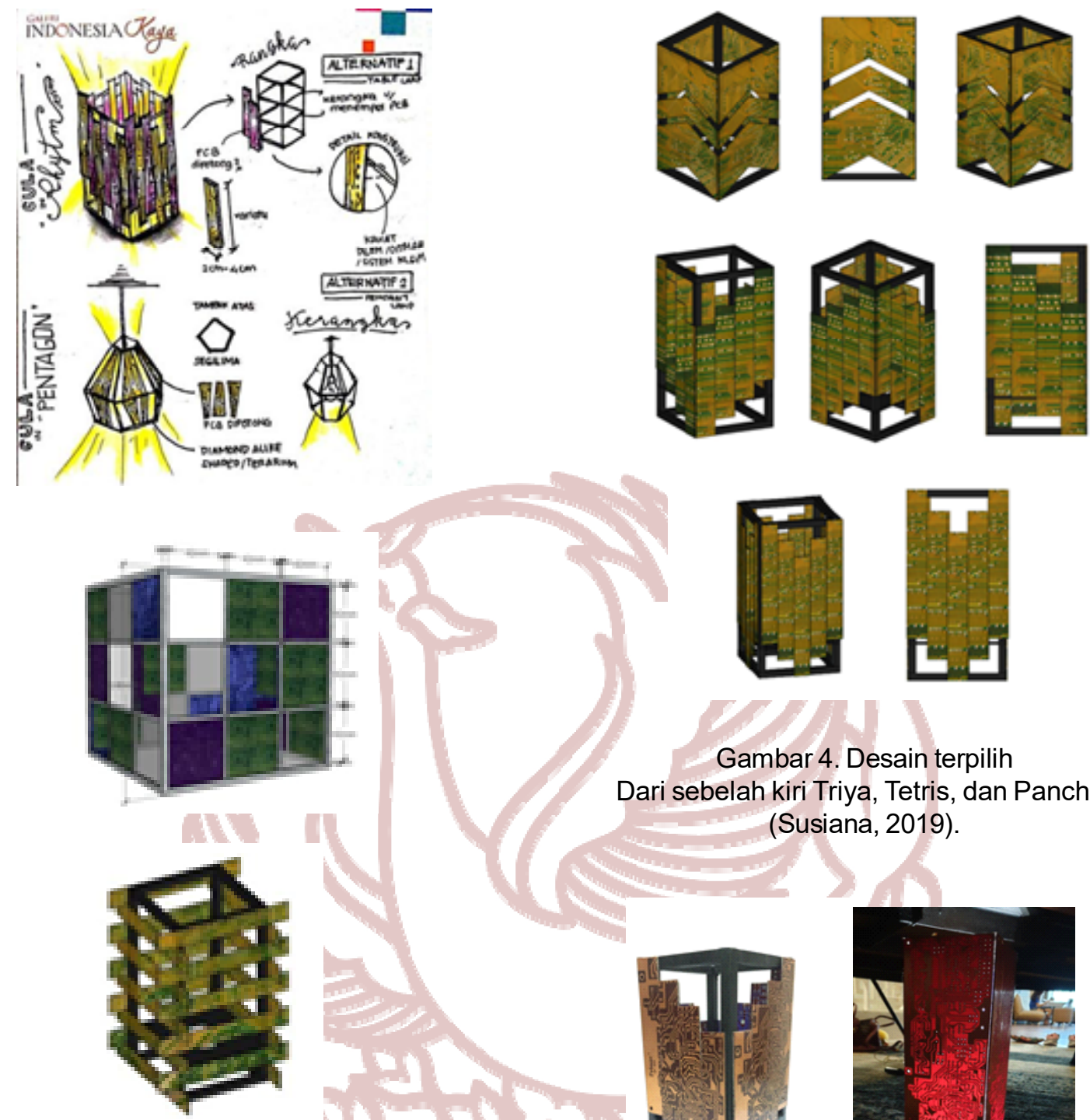

Gambar 4. Desain terpilih

Dari sebelah kiri Triya, Tetris, dan Pancha. (Susiana, 2019).

\section{Gambar 3. Sketsa Desain Awal} (Susiana, 2019).

\section{Experimentation}

Tahap experiment ini adalah tahap dimana memilih 3 desain terbaik dari tahap ideate yaitu berupa sketsa. Sketsa atau desain yang terpilih akan direalisasikan namun sebelum diberikan kepada customer, desain terpilih tersebut diuji coba terlebih dahulu dengan membuat prototype 1:1 bukan maket. Prototype yang sudah jadi akan dilihat dan di cek apakah desain tersebut pas dan tidak ada masalah teknis saat penggunaan dengan jangka waktu yang panjang. Desain-desain yang terpilih memiliki nama yang unik karena bentuknya yaitu Triya yang berbentuk segitiga, Tetris yang berbentuk persegi panjang dan disusun secara berjajar, dan Pancha yang memiliki bentuk seperti sayap.
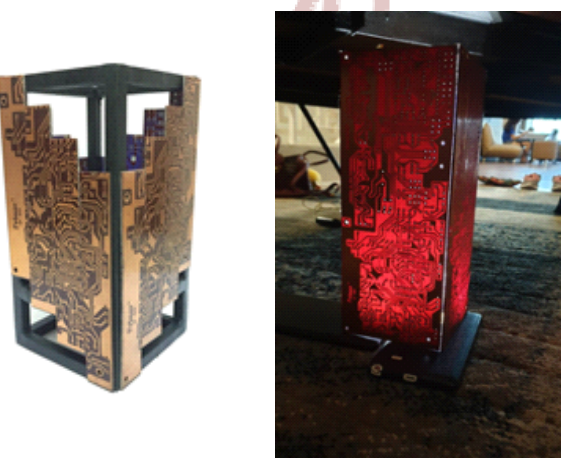

Gambar 5. Prototype Desain Terpilih. (Susiana, 2019)

\section{E. Evolution}

Pada tahap evolution ini penulis akan menguji coba produk tersebut untuk dijual di pasaran melalui 2 cara yaitu online dan offline. Pemasaran melalui online penulis menggunakan media sosial sebagai media pemasaran sedangkan untuk pemasaran secara offline dilakukan pada Bazar yang bertempat di Tunjungan Plaza Surabaya selama 3 hari yaitu pada hari Jumat- Minggu. 


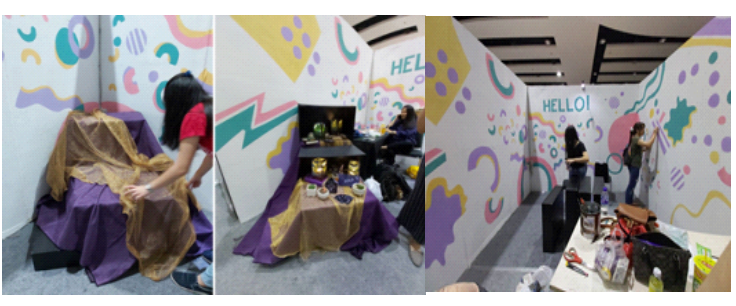

Gambar 6. Booth pada Bazar Untuk Pemasaran Dengan Sistem Offline.

(Susiana, 2019)
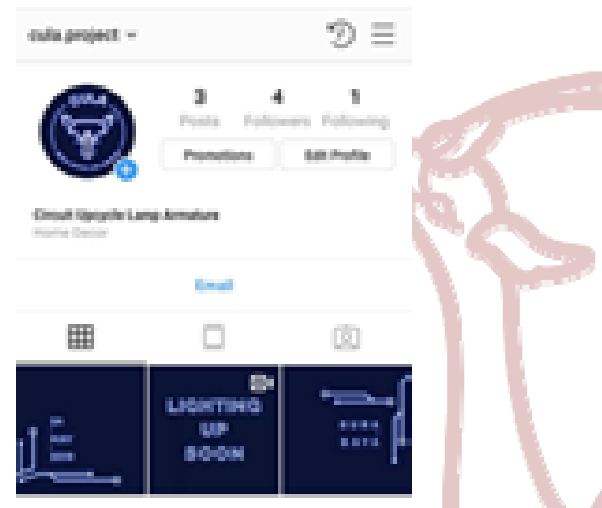

Gambar 7. Tampilan Instagram Untuk Pemasaran Online. (Gunawan, 2019).

\section{F. Test}

Pada tahap akhir ini lebih kepada hasil yang telah kita kerjakan selama ini dan dari hasil tersebut kita akan mendapatkan feedback dari customer pada saat pemasaran online maupun offline. Kumpulan datadata yang kita dapat dari pemasaran online maupun offline akan berupa kritik dan saran. Kritik dan saran yang penulis dapat akan dijadikan acuan untuk pengembangan produk armatur lampu ini menjadi lebih baik dan bervariasi.

\section{V.KESIMPULAN}

Perancangan produk "Pemanfaatan E-waste Printed Circuit Board Menjadi Armatur Lampu" merupakan salah satu alternatif upaya untuk mengurangi sampah e-waste, khususnya di Indonesia. Sampah e-waste dikenal berbahaya dan tidak memiliki nilai jual. Namun hal ini dapat dipatahkan oleh produk yang telah kami buat dan kami pasarkan ini, dapat diterima oleh masyarakat dan dapat bermanfaat menjadi aksesoris interior. Selain itu dengan adanya produk ini juga dapat membantu meningkatkan mitra-mitra lokal untuk dapat berkembang lagi dalam usahanya.

\section{UCAPAN TERIMAKASIH}

Penulis mengucapkan terima kasih kepada Tuhan Yang Maha Esa karena atas rahmat-Nya karya tulis ini bisa terselesaikan hingga akhir. Penulis juga berterima kasih kepada Dr. Laksmi Kusuma Wardani, S. Sn., M. Ds. selaku pembimbing dalam penulisan jurnal dan kepada Dr. Yusita Kusumarini, S. Sn., M. Ds. selaku pembimbing dalam pembuatan produk Printed Circuit Board Armature Lamp, serta kepada Nydia Velita, Shania Hwang Handoko, Agnes Nathania Hartono, dan Clarine Tiffany Harsono sebagai anggota kelompok perancangan produk ini.

\section{DAFTAR PUSTAKA}

Alfanaar, R. (2015). Studi Adsorpsi Dan Desorpsi Reduktif Pada Pembentukan Nanopartikel Emas Dari Printed Circuit Boards. Perpustakaan Pusat UGM, Yogyakarta.

Astuti, W., \& Damanhuri, E. (2012). Studi Persepsi Dan Perilaku Jasa Servis Dalam Memperpanjang Aliran Limbah Elektronik (EWaste) Di Kota Semarang. Prosiding Seminar Nasional Pengelolaan Sumberdaya Alam Dan Lingkungan.

Cahyono, H. B., \& Ariani, N. M. (2014). Reduksi Tembaga Dalam Limbah Cair Proses Etching Printing Circuit Board (PCB) Dengan Proses Elektrokimia. Jurnal Riset Industri, 8, 101-121.

Gramatyka, P., Nowosielki, R., Sakiewicz, P. (2007). Recycling of Waste Electrical and Electronic Equipment, Journal of Achievements of Materials and Manufacturing Engineering, 20, 535-538.

Josephine A. G., Santosa, A., dan Celline J. P. (2018). Perancangan Aksesoris Ruang Interior dengan Menggunakan Penggabungan Material Utama Keramik dan Besi. Jurnal Intra, 6, No. 2. 
M. Yudha P. A. N., Yunus, Z. (2015). Mesin Pengebor Printed Circuit Board (PCB) Otomatis.

Marwati, S. (2009). Kajian Tentang Kandungan LogamLogam Berharga Dalam Limbah Elektronik (E-Waste) Dan Teknik Recoverynya Melalui Proses Daur Ulang. Prosiding Seminar Nasional Penelitian, Pendidikan Dan Penerapan MIPA.
Osterwalder, A., \& Pigneur, Y. (2010). Business model generation: a handbook for visionaries, game changers, and challengers. Hoboken, $\mathrm{NJ}$ : Wiley.

Sadah, K., Fuada, S., \& Hidayati, N. (2015). Model Baru Dalam Penanganan Limbah Elektronik Di Indonesia Berbasis Integrasi Seni, Prosiding Sentia 2015 Politeknik Malang, 7.

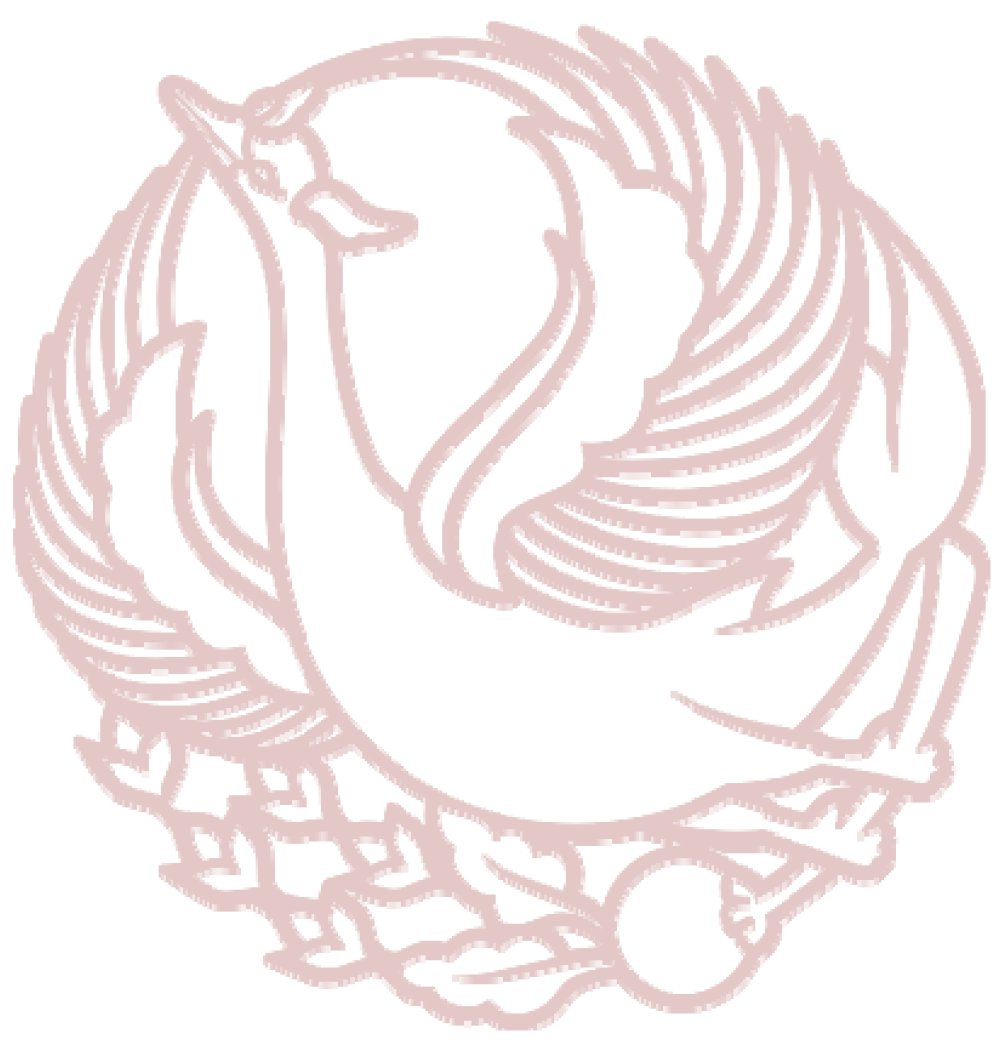

